\title{
Underutilization of gastroprotection for at-risk patients undergoing percutaneous coronary intervention: Spain compared with the United States
}

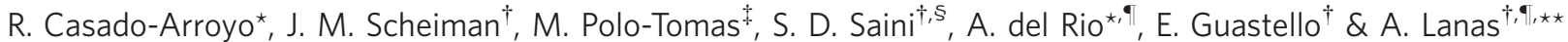

*Service of Cardiology, University

Hospital Lozano Blesa, Calle San Juan

Bosco 15, 50009 Zaragoza, Spain.

†Division of Gastroenterology,

Department of Internal Medicine,

University of Michigan Medical

Center, Ann Arbor, MI, USA

$\star_{+}$Cs, CIBERehd, Calle San Juan

Bosco 15, 50009 Zaragoza, Spain.

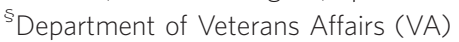

Health Services Research and

Development, Center of Excellence,

Center for Clinical Management

Research, Ann Arbor, MI, USA.

-University of Zaragoza Medical

School, Calle Domingo Miral s/n,

50009 Zaragoza, Spain.

**Division of Gastroenterology,

University Hospital Lozano Blesa,

C/San Juan Bosco 15, 50009

Zaragoza, Spain.

\section{Correspondence to:}

$\operatorname{Dr}$ A. Lanas, Division of

Gastroenterology, University Hospital Lozano Blesa, C/San Juan Bosco 15,

50009 Zaragoza, Spain.

E-mail: angel.lanas@gmail.com

\section{Publication data}

Submitted 9 March 2010

First decision 30 March 2010

Resubmitted 20 May 2010

Accepted 7 June 2010

EV Pub Online 6 July 2010

\section{SUMMARY}

\section{Background}

Proton pump inhibitors (PPIs) are the preferred agents for the prevention of aspirin-associated upper gastrointestinal bleeding (UGIB). Data are limited to determine whether PPIs are being used to reduce UGIB risk.

\section{Aim}

To evaluate the implementation of PPI treatment to reduce the GI risk in two cardiology centres from Europe and the United States.

\section{Methods}

A retrospective cross-sectional study was carried out at the University of Michigan and University Hospital-Zaragoza in 429 consecutive patients hospitalized for percutaneous coronary intervention (PCI) on dual antiplatelet therapy.

\section{Results}

Admission for PPI co-therapy was similar (34\% vs. 30\%) in both centres. At discharge, the proportion of high-risk patients receiving PPI therapy in the Spanish centre (75.4\%) was higher than their American peers (55.6\%) (OR: $2.5 ; 95 \% \mathrm{CI} ; 1.3-4.7$ ). No differences in PPI prescription rates were found among Spanish patients with/without GI risk factors. The opportunity to initiate PPI co-therapy in high-risk patients was missed in $81.8 \%$ $(36 / 44)$ of those not on PPI at admission in US patients vs. $24.1 \%(19 / 79)$ $(P<0.0001)$ in Spanish patients.

\section{Conclusions}

There are important differences concerning PPI prescription and risk stratification in the two centres when managing PCI patients. Efforts to stratify risks and utilize appropriate strategies for UGIB prophylaxis in high-risk patients are warranted. 


\section{R. Casado-Arroyo et al.}

\section{INTRODUCTION}

Dual antiplatelet therapy with aspirin (ASA) in addition to clopidogrel (CLP) reduces recurrent cardiovascular events in acute coronary syndrome among patients treated medically or with percutaneous coronary intervention (PCI). ${ }^{1,2}$ It is also well established that ASA is associated with a twofold increased risk of upper gastrointestinal bleeding (UGIB), which is further increased when combined with CLP therapy. The presence of independent ulcer risk factors that include age $>70$, previous ulcer history (complicated $>$ uncomplicated), Helicobacter Pylori infection and concomitant therapy with anticoagulants, NSAIDs or steroids are well established..$^{3-7}$

A recent consensus document published by the American College of Gastroenterology, ${ }^{8}$ the American College of Cardiology Foundation and the American Heart Association concludes that proton pump inhibitors (PPI) should be considered in any person with risk factors for gastrointestinal bleeding receiving antiplatelet therapy. ${ }^{9}$ After PCI therapy, patients are prescribed dual antiplatelet therapy with ASA and CLP, putting these patients at GI risk, especially among those patients with additional risk factors. Therefore, physicians must evaluate the GI risk profile and adopt prevention therapies in an attempt to reduce GI complications. ${ }^{10,11}$ The consensus document was motivated, in part, by the hypothesis that non-GI physicians did not systematically consider UGIB risk or respond with appropriate gastroprotective strategies.

Although some concerns have been raised that the coadministration of a PPI with CLP could pose a risk of drug interaction via cytochrome $\mathrm{P} 4502 \mathrm{C} 19,{ }^{11,12}$ and therefore have the potential to increase the risk of $\mathrm{CV}$ events, ${ }^{11,13}$ the recommendations of the panel have not been changed for reasons of lack of firm evidence of a clinically important interaction leading to worsened CV outcomes. However, regulatory agencies have proposed warnings that careful evaluations of the $\mathrm{CV}$ and GI risks should be undertaken in the individual patient. ${ }^{14,15}$ Furthermore, as more recent data suggest that the potential interaction between these two drugs may have no clinical impact on $\mathrm{CV}$ events, ${ }^{16}$ and as other therapeutic alternatives such as misoprostol, H2-blockers or $H$. pylori eradication have still poor evidence of being effective as preventive strategies, ${ }^{10}$ PPI co-therapy still remains the main prevention therapy for those at risk taking antiplatelet therapy.

No study has evaluated whether PPIs are being prescribed to reduce UGIB risk in at-risk patients on dual antiplatelet therapy after PCI. We also sought to deter- mine whether there are different prescription habits between centres in different countries.

\section{METHODS}

\section{Study design and setting}

The study was designed as a retrospective cross-sectional study of medical records at the University Hospital Lozano Blesa in Zaragoza (Spain) and at the University of Michigan Medical School (US). Patients admitted to the hospital for PCI between January 2007 and December 2007 were eligible for inclusion. Data were obtained from charts after discharge and included basic demographic information, date of hospitalization and discharge, cause of hospitalization, presence of co-morbidities, cardiovascular events and GI bleeding during hospitalization. Medical treatment received by patients before and during hospitalization and prescription issued at discharge were also recorded. The ethics committee in both centres reviewed and approved the study protocol.

\section{Patients}

A total of 429 patients met the inclusion criteria and were studied.

\section{Interventions}

None.

\section{Main outcome measures}

All patients included in the study were hospitalized to undergo PCI from coronary heart disease (acute myocardial infarction, unstable or stable angina). Risk factors considered for UGIB were age $>70$, ulcer history and concomitant therapy with anticoagulants, NSAIDs or steroids. ${ }^{3,}{ }^{4,} 6$ Patients with $\geq 1$ risk factor (in addition to dual antiplatelet therapy) were defined as 'high-risk' (HR) for UGIB. The proportion of patients at discharged on PPI therapy was calculated and stratified by GI bleeding risk. All patients received low-dose ASA therapy (75 or $162 \mathrm{mg} /$ day) in addition to CLP $75 \mathrm{mg} /$ day. A loading dose (300 $\mathrm{mg}$ of CLP) was administered as appropriate.

\section{Statistics}

We assumed that the average rate of Spanish patients on PPI at discharge was $60 \%$, and that of the US patients, $40 \%$. Therefore, we planned to enrol approximately 140 patients in each study group who could be evaluated for the study to have $90 \%$ power to detect a significant difference in the rates of patients discharged on PPI 
between the two centres with a two-tailed significance level of 0.005 or less. Statistical differences and odds ratios were calculated using Chi-square test for discrete variables and $t$-tests for continuous variables (expressed as mean values and standard deviation). All statistical tests were performed with the use of SPSS software (SPSS v14, Chicago, IL, USA).

\section{RESULTS}

Table 1 defines the patient demographics and clinical characteristics of the study population. Patients from the Spanish centre were older than those from the US, translating into a higher proportion of patients at high GI risk in the Spanish population. However, the Americans had significantly more cardiovascular co-morbidities (hypertension, hypercholesterolemia and diabetes). American patients were also more frequently on cardiovascular medications on admission. There were no differences regarding GI ulcer history in the Americans. PPI treat- ment at admission was also similar (Table 1). The two most frequent reasons for PPI at admission among Americans were gastro-oesophageal reflux disease in $22.6 \%(n=45)$ and past history of GI bleeding in $4.5 \%$ $(n=9)$. No reasons for PPI use were recorded among most Spanish patients in the admission documents and therefore these data are not reported here for the Spanish cohort.

Of the Spanish patients not on PPI before admission [70\% of the cohort $(n=161)$ ], $49.7 \%(n=80)$ had 1 or more GI risk factors and 50.3\% $(n=81)$ were low-risk patients. Similarly, for the Americans not on PPI before admission [68\% of the cohort $(n=131)], 34.4 \%(n=45)$ were HR patients and $65.6 \%(n=86)$ were low-risk patients.

During hospitalization (Table 2), 93\% $(n=185)$ of the American and $96.7 \%(n=223)$ of the Spanish patients had a coronary stent placed. Two patients died during hospitalization - one of complications with anoxic brain

\section{Table 1 | Baseline characteris-} tics of study participants

\begin{tabular}{|c|c|c|c|}
\hline & $\begin{array}{l}\text { Spanish patients } \\
(n=230)\end{array}$ & $\begin{array}{l}\text { US patients } \\
(n=199)\end{array}$ & $P$-value \\
\hline Age, mean (s.d.) & $67.4(8.9)$ & $62.5(11.7)$ & $<0.0001$ \\
\hline Male gender & $193(83.9)$ & $154(77.4)$ & 0.0877 \\
\hline Age $>70$ & $95(41.3)$ & $49(24.6)$ & 0.0003 \\
\hline NSAID use & $15(6.5)$ & $17(8.5)$ & 0.4308 \\
\hline Ulcer history & $13(5.7)$ & $17(8.5)$ & 0.2570 \\
\hline Steroids (>10 mg daily) use & $7(3.0)$ & $5(2.5)$ & 0.7529 \\
\hline Oral anticoagulants & $11(4.8)$ & $14(7.0)$ & 0.3318 \\
\hline High-risk Gl patients & $116(50.4)$ & $82(41.2)$ & 0.0566 \\
\hline Hypertension & $126(54.8)$ & $147(73.9)$ & $<0.0001$ \\
\hline Hypercholesterolemia & $133(57.8)$ & $151(75.9)$ & 0.0001 \\
\hline Diabetes mellitus & $60(26.1)$ & $72(36.2)$ & 0.0238 \\
\hline Previous CABG & $5(2.2)$ & $38(19.1)$ & $<0.0001$ \\
\hline $\begin{array}{l}\text { Previous stroke or transient } \\
\text { ischaemic attack }\end{array}$ & $14(6.1)$ & $22(11.0)$ & 0.0677 \\
\hline \multicolumn{4}{|l|}{ At admission on } \\
\hline No antiplatelet agent & $120(52.2)$ & $64(32.2)$ & $<0.0001$ \\
\hline ASA alone & $61(26.5)$ & $88(44.2)$ & 0.0001 \\
\hline Clopidogrel alone & $3(1.3)$ & $4(2)$ & 0.5674 \\
\hline ASA and clopidogrel & $45(19.6)$ & $43(21.6)$ & 0.6090 \\
\hline PPI & $69(30)$ & $68(34.2)$ & 0.3522 \\
\hline Statins & 89 (38.7) & 114 (57.3) & 0.0001 \\
\hline
\end{tabular}

Values are expressed as $n$ (\%), unless specified.

$C A B G$, coronary artery bypass graft; PPI, proton pump inhibitor. 


\begin{tabular}{lccr}
\hline & $\begin{array}{l}\text { Spanish } \\
\text { patients } \\
(n=230)\end{array}$ & $\begin{array}{l}\text { US patients } \\
(n=199)\end{array}$ & $P$-value \\
\hline Stent placement & $224(97.4)$ & $185(93.0)$ & 0.0307 \\
High-risk Gl patients on PPI & $87 / 116(75.0)$ & $37 / 82(45.1)$ & $<0.0001$ \\
Low-risk GI patients on PPI & $80 / 114(70.1)$ & $31 / 117(26.5)$ & $<0.0001$ \\
In-hospital GI bleeding complications & $2(0.9)$ & $1(0.5)$ & 0.7724 \\
$\begin{array}{l}\text { In-hospital death } \\
\text { Length of hospitalization (days), } \\
\text { mean (s.d.) }\end{array}$ & $2(0.9)$ & $2(1.0)$ & 0.9150 \\
\hline
\end{tabular}

Values are expressed as $n(\%)$, unless specified.

$\mathrm{GI}$, gastrointestinal; PPI, proton pump inhibitor.

\begin{tabular}{|c|c|c|c|}
\hline & $\begin{array}{l}\text { Spanish patients } \\
(n=228)\end{array}$ & $\begin{array}{l}\text { US patients } \\
(n=197)\end{array}$ & $P$-value \\
\hline Dual antiplatelet agents & $223(97.8)$ & $196(99.5)$ & 0.1385 \\
\hline PPI & $171(75.0)$ & $82(41.2)$ & $<0.0001$ \\
\hline $\begin{array}{l}\text { High-risk Gl patients } \\
\text { on PPI at discharge }\end{array}$ & $86 / 114(75.4)$ & $45 / 81(55.6)$ & 0.0037 \\
\hline $\begin{array}{l}\text { Low-risk Gl patients } \\
\text { on PPI at discharge }\end{array}$ & $83 / 114(72.8)$ & $36 / 116(31.0)$ & $<0.0001$ \\
\hline Bleeding in follow-up & $3(1.3)$ & $4(2.0)$ & 0.5692 \\
\hline \multicolumn{4}{|c|}{ Values are expressed as $n(\%)$} \\
\hline \multicolumn{4}{|c|}{ GI, gastrointestinal; PPI, proton pump inhibitor. } \\
\hline
\end{tabular}

Table 2 | In-hospital

management

\author{
Table 3 | At discharge \\ management
}

injury and another because of septic shock in the Spanish centre, and two patients in the US due to ventricular fibrillation and anoxic brain injury. The proportion of patients who received PPI therapy during hospitalizations was high and increased when compared with those receiving PPI at admission, especially in the Spanish cohort in both high- and low-risk GI patients, whereas that proportion was much lower in the US patients (Table 2). Three patients (two from Spain and one from the US centre) had an in-hospital GI bleeding after the interventional procedure (the three were on a PPI and two were HR patients).

At discharge (Table 3), 419 (98.5\%) of the 425 patients of entire population were on dual antiplatelet therapy; two of 197 (1\%) of the US patients and none of the Spanish were on aspirin alone. Overall, in the Spanish centre, 171/228 (75.0\%) patients were prescribed PPI therapy at discharge vs. $81 / 197(41.1 \%)$ patients in the US (OR: $4.3 ; 95 \%$ CI: 2.8, 6.6; $P<0.0001$ ). When patients discharged from hospital were stratified according to the presence of risk factors (Figure 1), PPI rates were similar in patients with no risk factors (83/114; $73 \%)$ or one or more risk factors $(86 / 114 ; 75.4 \%)$ in the Spanish centre $(P=0.679)$, whereas the Americans with no risk factors $(36 / 116 ; 31.0 \%)$ differed from the HR cases $(45 / 81 ; 55.6 \%)(P=0.0006)$.

Overall, HR American patients were more likely than low-risk patients to be discharged on a PPI $(\mathrm{OR}=2.8$, 95\% CI: $1.5-5.2, P=0.0007)$. In both centres, the proportion of PPI therapy increased further for those patients with one or more risk factors (Figure 2). Table 4 also includes PPI prescription rates according to individual risk factors. Figures were always higher for the Spanish cohort. Considering HR patients not on PPI at admission (80 of 116 among the Spanish cohort and 45 of 82 in the US cohort; of the two Spanish patients who died during hospitalization, both were HR and one was on PPI, whereas of the two Americans, one was HR and 


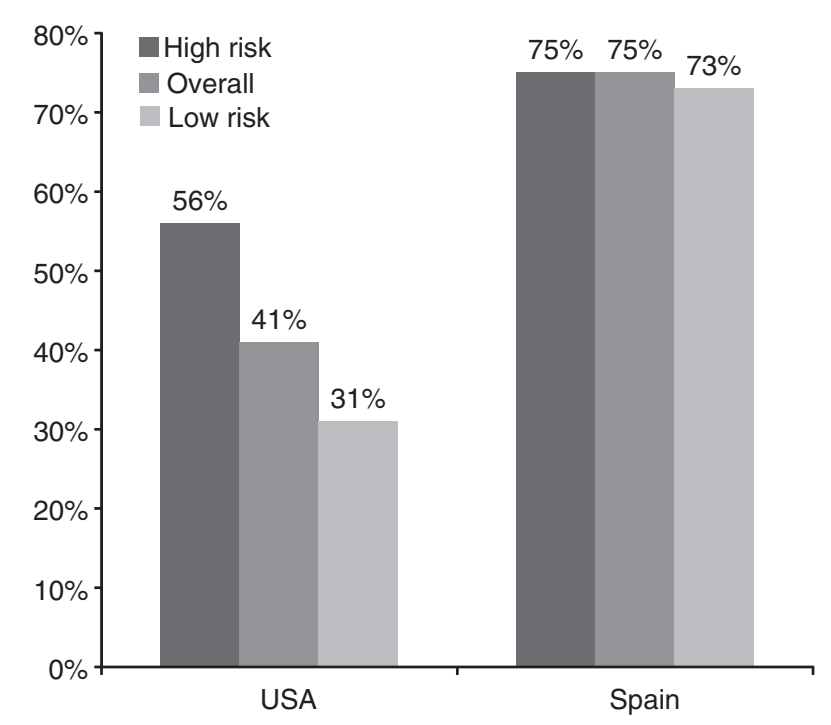

Figure 1 | Proton pump inhibitor prescription at discharge: US vs. Spain.

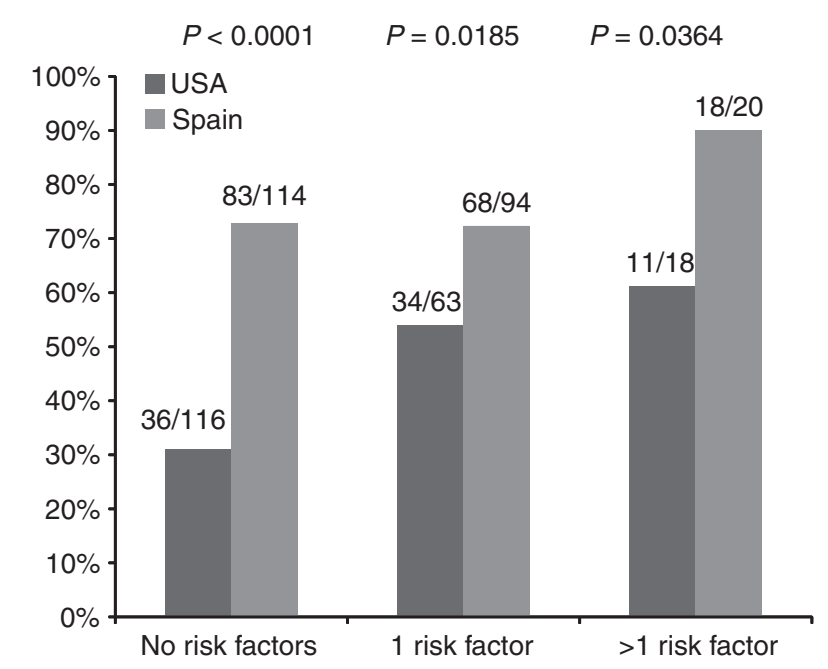

Figure 2 | Proton pump inhibitor therapy at discharge in relation to $\mathrm{GI}$ risk factors.

not on PPI), the opportunity to initiate PPI co-therapy following PCI and treatment with dual antiplatelet therapy at discharge in this population was missed in $81.8 \%$ $(36 / 44)$ of the US patients. In the Spanish cohort, the proportion was $24.1 \%(19 / 79)(P<0.001)$, but seven additional HR patients on PPI at admission were discharged with no PPI, which means that in this cohort, the overall opportunity was missed in $22.8 \%$ (26/114) of patients.

\section{DISCUSSION}

According to current recommendations, patients at risk for UGIB receiving dual antiplatelet therapy with ASA and CLP should receive PPI co-therapy. ${ }^{8,11,17-19}$ Our study shows that the probability of receiving PPI therapy at hospital discharge varied significantly among the two centres studied. We found that the proportion of patients being prescribed PPI at discharge in the Spanish centre was significantly higher than that observed in patients from the US. The data should be of interest, as no study has reported transatlantic prescription habits in this type of patients. ${ }^{20-22}$ As the study collected information from patients records before concerns on the potential interaction of PPI with CLP were raised, the data reflect the awareness among the cardiologists in those centres on the necessity for risk assessment and response with co-prescription to reduce the risk of UGIB. We suspect that the more recent developments concerning the potential interaction of CLP with PPI may have significantly reduced co-prescription rates.

It remains unclear whether the data observed in these two centres reflect prescription habits among all cardiologists in other practice settings in their respective countries. However, we suggest that it may well be the case, as data on GI bleeding and drug use, for example, from at least one of the centres (Zaragoza), have been often reproduced in other centres of the same country. ${ }^{23,} 24$

From the data reported here, it can be concluded that cardiologists in the Spanish centre are more concerned about the UGIB risk associated with dual antiplatelet therapy than their American peers, even before the recommendations of the consensus document were published. $^{5}$ However, the data show that the PPI prescription observed in the Spanish centre was not guided by the assessment of the underlying UGI risk factors, as the prescription of PPI is essentially independent of the presence of and the number of GI risk factors. On the contrary, this was the case in the US centre, but the gap of risk reducing co-therapy in high patients was much larger than in Spain, which reduces the overall clinical impact, and still, a significant proportion of the group of HR patients for UGIB were not started on PPI in both centres.

The reasons for the differences in PPI prescription rates found in both centres, which could be generalized to other centres in the respective countries, remain unclear. Differences are unlikely to be driven by a patient's economic 


\begin{tabular}{|c|c|c|c|}
\hline & $\begin{array}{l}\text { Spanish patients } \\
(n=228)\end{array}$ & $\begin{array}{l}\text { US patients } \\
(n=197)\end{array}$ & $P$-value \\
\hline No risk factors & $83 / 114(72.8)$ & $36 / 116(31.0)$ & $<0.0001$ \\
\hline 1 Risk factor & $68 / 94(72.3)$ & $34 / 63(54.0)$ & 0.0185 \\
\hline$>1$ Risk factor & $18 / 20(90.0)$ & $11 / 18(61.1)$ & 0.0364 \\
\hline Age $\geq 70$ years old & 71/93 (76.3) & $28 / 49(57.1)$ & NS \\
\hline Previous history of peptic ulcer disease & $11 / 13(84.6)$ & $12 / 17(70.6)$ & NS \\
\hline Concurrent warfarin use & $9 / 11(81.8)$ & $7 / 14(50)$ & NS \\
\hline Concurrent use of corticosteroids $\geq 10 \mathrm{mg}$ daily & $7 / 7(100.0)$ & $4 / 5(80)$ & NS \\
\hline Concurrent use of non-aspirin NSAIDs & $13 / 15(86.7)$ & $7 / 17(41.2)$ & 0.0328 \\
\hline
\end{tabular}

Values are expressed as $n(\%)$.

concerns, although the fact that medications are widely subsidized by the health system in the European centre may facilitate prescription to patients, especially if $\mathrm{CV}$ safety is not of concern. More likely the differences may be due to different perceptions on the intrinsic GI risk of antiplatelet therapies, as PPIs are widely prescribed across Spain to patients receiving potential gastro-toxic agents such as NSAIDs. ${ }^{25}$ In any case, the lack of selectivity of PPI prescription in the Spanish centre and the wide gap of that in at-risk patients in the American one show that there is a clear opportunity to better educate physicians better on the importance of gastroprotection in this group of patients and develop better educational programmes to disseminate the appropriate guidelines towards the goal of reducing UGIB.

The strengths of our study include the use of welldefined risk factors and end points as well as the use of structured data collection from hospital medical records (electronic in US and manual review of charts in Spain), which contained all the data required for the study. There are also limitations of our study. The first is that our analysis was based on medical and prescription records. A systematic assessment of medication compliance was not possible due to the study design. While this is an important consideration, it should be noted that the purpose of this study was to describe prescription patterns of physicians in two different countries. Another weakness is that GI bleeding risk may have been considered by the prescribers, but other aspects in the decision-making process, including cost and insurance reimbursement policies, are not or may not be documented and, however, have a clear impact on the observed differences.

In summary, our data provide evidence that GI risk reduction strategies are not considered routinely for at-risk patients on dual antiplatelet agents and that co-therapy to reduce risk varies widely across centres from two different countries. Our study also demonstrates that prescription may not always be based on proper assessment of risk factors. We conclude that future efforts be implemented to improve the rates of GI risk assessment and of prevention strategies among the HR population as well as future studies to assess the GI and $\mathrm{CV}$ impact of these strategies.

\section{ACKNOWLEDGEMENTS}

Declaration of personal interests: The authors are grateful for the collaboration of the Service of Cardiology in Spain and Michigan. Angel Lanas has served as consultant to AstraZeneca, Pfizer, Bayer and Nicox, and has received research funding from AstraZeneca and Pfizer for investigator-initiated research. James Scheiman has served as consultant to AstraZeneca as well as Takeda, Bayer and Pozen, Inc. Ruben Casado-Arroyo, Elizabeth Guastello, Samir D Saini and Alfonso Del Rio report no conflict of interest. Declaration of funding interests: This study was funded by Grant B01 from the Regional Aragonés Government in Spain. A grant from AstraZeneca to the University of Michigan partially supported the study in the US. Data analysis and writing of this paper was carried out exclusively by the authors. 


\section{REFERENCES}

1. Antman EM, Hand M, Armstrong PW, et al. 2007 focused update of the ACC/AHA 2004 guidelines for the management of patients with ST-elevation myocardial infarction: a report of the American College of Cardiology/American Heart Association Task Force on Practice Guidelines (Writing group to review new evidence and update the ACC/AHA 2004 guidelines for the management of patients with ST-elevation myocardial infarction). J Am Coll Cardiol 2008; 51: 210-47.

2. Anderson JL, Adams CD, Antman EM, et al. ACC/AHA 2007 guidelines for the management of patients with unstable angina/non-ST-elevation myocardial infarction: a report of the American College of Cardiology/American Heart Association Task Force on Practice Guidelines (Writing Committee to Revise the 2002 Guidelines for the Management of Patients With Unstable Angina/Non-ST-Elevation Myocardial Infarction) developed in collaboration with the American College of Emergency Physicians, the Society for Cardiovascular Angiography and Interventions, and the Society of Thoracic Surgeons, endorsed by the American Association of Cardiovascular and Pulmonary Rehabilitation and the Society for Academic Emergency Medicine. J Am Coll Cardiol 2007; 50: e1-157.

3. Scheiman JM. NSAIDs, gastrointestinal injury, and cytoprotection. Gastroenterol Clin North Am 1996; 25: 279-98.

4. Lanas A, Scheiman J. Low-dose aspirin and upper gastrointestinal damage: epidemiology, prevention and treatment. Curr Med Res Opin 2007; 23: 163 73.

5. Hallas J, Dall M, Andries A, et al. Use of single and combined antithrombotic therapy and risk of serious upper gastrointestinal bleeding: population based case-control study. BMJ 2006; 333 : 726.

6. Johnson DA. Upper GI risks of NSAIDs and antiplatelet agents: key issues for the cardiologist. Rev Cardiovasc Med. 2005; 6(Suppl. 4): S15-22.
7. Scheiman JM, Fendrick AM. Summing the risk of NSAID therapy. Lancet 2007; 369: $1580-1$.

8. Bhatt DL, Scheiman J, Abraham NS, et al. ACCF/ACG/AHA 2008 Expert consensus document on reducing the gastrointestinal risks of antiplatelet therapy and NSAID use: a report of the Consensus Documents American College of Cardiology Foundation Task Force on Clinical Expert. Circulation 2008; 118: 1894-909.

9. Antman EM, Bennett JS, Daugherty A, Furberg C, Roberts H, Taubert KA. Use of nonsteroidal antiinflammatory drugs: an update for clinicians: a scientific statement from the American Heart Association. Circulation 2007; 115: 1634-42.

10. Bavry AA, Bhatt DL. Appropriate use of drug-eluting stents: balancing the reduction in restenosis with the concern of late thrombosis. Lancet 2008; 371: 2134-43.

11. Ho PM, Maddox TM, Wang L, et al. Risk of adverse outcomes associated with concomitant use of clopidogrel and proton pump inhibitors following acute coronary syndrome. JAMA 2009; 301: 937-44.

12. Simon T, Verstuyft C, Mary-Krause M, et al. Genetic determinants of response to clopidogrel and cardiovascular events. N Engl J Med 2009; 360: 363-75.

13. Norgard NB, Mathews KD, Wall GC. Drug-drug interaction between clopidogrel and the proton pump inhibitors. Ann Pharmacother 2009; 43: 1266-74.

14. European Medicines Agency. Public Statement on Possible Interaction Between Clopidogrel and Proton-Pump Inhibitors. London, UK: European Medicines Agency, 2009.

15. Food and Drug Administration. Early Communication About an Ongoing Safety Review of Clopidogrel Bisulfate (marketed as Plavix). Silver Spring, MD: Food and Drug Administration, 2009.

16. O’Donoghue ML, Braunwald E, Antman $\mathrm{EM}$, et al. Pharmacodynamic effect and clinical efficacy of clopidogrel and prasugrel with or without a proton-pump inhibitor: an analysis of two randomised trials. Lancet 2009; 374: 989-97.
17. Yusuf S, Zhao F, Mehta SR, Chrolavicius S, Tognoni G, Fox KK. Effects of clopidogrel in addition to aspirin in patients with acute coronary syndromes without ST-segment elevation. $N$ Engl J Med 2001; 345: 494-502.

18. Bavry AA, Bhatt DL. Drug-eluting stents: dual antiplatelet therapy for every survivor? Circulation 2007; 116: 696-9.

19. Chan FK, Ching JY, Hung LC, et al. Clopidogrel versus aspirin and esomeprazole to prevent recurrent ulcer bleeding. N Engl J Med 2005; 352: 238-44.

20. Khurram Z, Chou E, Minutello R, et al. Combination therapy with aspirin, clopidogrel and warfarin following coronary stenting is associated with a significant risk of bleeding. J Invasive Cardiol 2006; 18: $162-4$.

21. CAPRIE Steering Committee. A randomised, blinded, trial of clopidogrel versus aspirin in patients at risk of ischaemic events (CAPRIE). Lancet 1996; 348: 1329-39.

22. Serebruany VL, Steinhubl SR, Berger PB, et al. Analysis of risk of bleeding complications after different doses of aspirin in 192,036 patients enrolled in 31 randomized controlled trials. Am J Cardiol 2005; 95: 1218-22.

23. Lanas A, García-Rodríguez LA, Arroyo MT, et al. Risk of upper gastrointestinal ulcer bleeding associated with selective cyclo-oxygenase- 2 inhibitors, traditional non-aspirin non-steroidal antiinflammatory drugs, aspirin and combinations. Gut 2006; 55: 1731-8.

24. Lanas A, García-Rodríguez LA, Arroyo MT, et al. Effect of antisecretory drugs and nitrates on the risk of ulcer bleeding associated with nonsteroidal antiinflammatory drugs, antiplatelet agents, and anticoagulants. Am J Gastroenterol 2007; 102: 507-15.

25. Lanas A, Esplugues JV, Zapardiel J, Sobreviela E. Education-based approach to addressing non-evidence-based practice in preventing NSAID-associated gastrointestinal complications. World J Gastroenterol 2009; 15: 5953-9. 